Journal of Southeast Asian

\title{
Southeast Asian Refugee-Learners: Identities Informing ESL Education and Support
}

Andrew J. Perlman

perlmanence@gmail.com

Follow this and additional works at: https://docs.lib.purdue.edu/jsaaea

Part of the Bilingual, Multilingual, and Multicultural Education Commons

\section{Recommended Citation}

Perlman, Andrew J. (2020) "Southeast Asian Refugee-Learners: Identities Informing ESL Education and Support," Journal of Southeast Asian American Education and Advancement. Vol. 15 : Iss. 1, Article 4. DOI: $10.7771 / 2153-8999.1179$

Available at: https://docs.lib.purdue.edu/jsaaea/vol15/iss1/4

This document has been made available through Purdue e-Pubs, a service of the Purdue University Libraries. Please contact epubs@purdue.edu for additional information.

This is an Open Access journal. This means that it uses a funding model that does not charge readers or their institutions for access. Readers may freely read, download, copy, distribute, print, search, or link to the full texts of articles. This journal is covered under the CC BY-NC-ND license. 
Southeast Asian Refugee-Learners: Identities Informing ESL Education and Support

\section{Cover Page Footnote}

I would like to thank to my advisor, Dr. Christopher Jones, for his guidance and support in the early stages of writing this paper. Additionally, I would like to thank my mom, Elizabeth Perlman, for her unending patience, support and editing expertise, as well as Juno Lin for her crucial encouragement during the home stretch. 


\title{
JSAAEA Journal of Southeast Asian American
Education and Advancement
}

Vol. 15 Iss. 1 (2020)

WWW.JSAAEA.org

\section{Southeast Asian Refugee-Learners: Identities Informing ESL Education and Support}

\author{
Andrew J. Perlman
}

\begin{abstract}
Serving as a synthesis of previously published studies and digests, this paper focuses on Southeast Asian refugees in America to address the complex interaction between refugee-learners' ongoing construction of identity and the English as a Second Language (ESL) environment. Drawing on a wealth of historical and contemporary research on one of America's most prominent refugee populations, this exploration highlights the traits that constitute Southeast Asians as a unique group of learners due to their shared histories of trauma; social, cultural and religious influences; and ongoing sociocultural and linguistic negotiations of identity during resettlement. As a result, ESL programs and practitioners become critical to both language acquisition and sociocultural support of both Southeast Asian and other refugee-learners. Reflecting this dynamic nature of the learner-program relationship, this paper also offers curriculum- and teacher-specific suggestions for engaging and empowering both Southeast Asians and other refugee populations through ESL instruction. The goal of this survey is to raise awareness of refugee-learner identity and second language acquisition as a means of promoting further dialogue among ESL practitioners.
\end{abstract}

Keywords: Southeast Asia, Laos, Cambodia, Hmong, Refugees, ESL, Identity, Trauma, Gender, Social roles, Second language acquisition, Curriculum, Teacher roles, Sociolinguistics

\footnotetext{
@)

SDRERIIGHISRESERNEDR Readers are free to copy, display, and distribute this article, as long as the work is attributed to the author(s) and the Journal of Southeast Asian American Education \& Advancement, it is distributed for non-commercial purposes only, and no alteration or transformation is made in the work. More details of this Creative Commons license are available at http://creativecommons.org/licenses/by-nc-nd/3.0/. All other uses must be approved by the author(s) or JSAAEA.

Journal of Southeast Asian American Education \& Advancement, Vol. 15. Iss. 1. (2020) ISSN: 2153-8999
} 


\section{Introduction}

Beginning in the mid-1970s with the American withdrawal from Vietnam and political violence in both Cambodia and Laos, millions of refugees fled their homelands in Southeast Asia for the relative safety of camps in neighboring Asian countries. Eventually many of these refugees resettled in the United States with the help of the United Nations and other support groups. For them, life in a new environment presented innumerable challenges as they struggled to make sense of past trauma and negotiate new bilingual and bicultural identities. Unfortunately, history is repeating itself, with war, persecution and human rights violations by governments of Southeast Asian countries, most recently Myanmar, perpetuating violence that forever changes the lives of many innocent citizens. As a result, resettlement in the United States remains a contemporary reality for many Southeast Asian refugees, a demographic accounting for $16 \%$ of refugees admitted to the United States in 2017-2018, according to the U.S. Department of State refugee admissions report (2018).

Over the past 40 years, both newly settled Southeast Asian refugees as well as secondgeneration children born to refugee parents have been an ever-growing population in the United States. In fact, John Tenhula, in his book, Voices from Southeast Asia, states that "Southeast Asian refugees make up the largest Asian refugee group ever admitted to the United States," distinguished by their racial and demographic identities (Tenhula, 1991, p. 5). As a unique cohort, Southeast Asian refugees in America, therefore, present different challenges in the resettlement process. Beyond each individual's story of survival and struggle in the face of both involuntary displacement from their homes and resettlement in the United States, these Southeast Asian refugees share experiences of redefining their identities in new sociocultural and linguistic contexts, constituting a distinct type of ESL learner.

Underlying the shared refugee experience of forced migration, life in refugee camps, and third country resettlement, trauma affects all individuals and their place within the family and community. This experience of uprooted existence is compounded by the differences between familiar language and culture and those of the new living environment. As refugees begin to construct their dynamic, contextual identities and develop personal investments in language learning, ESL programs and instructors are often called upon to reflexively meet the needs of learners as both victims of trauma and burgeoning bicultural, bilingual speakers. ESL programs, therefore, become both a physical context for refugees to learn English as well as a broader support system for their resettlement. Consequently, the refugee-ESL relationship becomes an interactional dialogue, rather than a static script, as a means of expanding language learning beyond the classroom to the real-life experiences and daily challenges of refugees in America. For Southeast Asian learners, in particular, social values and mores as well as cultural learning styles further influence this relationship between trauma and ESL learning.

In order to better understand the vital learner-program-teacher relationship, this paper presents a survey of previously published works focusing mainly on adult Southeast Asian ESL learners, due to the group's historic prominence among recent refugee newcomers. Additionally, this survey explores unique influences on refugee-learner identities while also outlining successful engagement of both Southeast Asian and other communities of refugee-learners' roles of both cultural-linguistic agents and classroom-participants. Tracing the identity of these refugee-learners through their previous experiences of trauma, including sociocultural and linguistic factors, as well as the responsibilities of ESL programs and instructors, this exploration aims to further advance the understanding of second language acquisition in the context of the refugee experience. To meet 
the needs of refugees entering and adjusting to life in the United States, this knowledge, understanding and empathy will aid ESL practitioners and volunteers in their continuing efforts to support refugees' self-empowerment as they become bicultural, bilingual English speakers.

Offering a synthesis of published studies, articles and digests, the aim of this investigation is to address the surprising lack of refugee-specific ESL programs and specialized instructor training in the United States. Presented in two sections, focusing first on the refugee-learner identity and next on refugee-learner engagement, it is hoped that this work will not only create a dialogue among ESL practitioners, but also lay the foundation for effective change in the way English is fostered in the lives of Southeast Asian and other refugees living in America.

\section{Refugee-Learner Identity}

As profiled in many sources, refugee-learners constitute a unique population within the ESL context. In addition to shared experiences, cultural values and religious beliefs among Southeast Asian refugees, their learner identities are also influenced by histories of violence and trauma, which can affect all aspects of their lives, including second language acquisition. Additionally, new gender roles, sociocultural contexts and bilingual, bicultural struggles affect them as they forge new identities in America.

\section{On Identity \& Literacy}

Before delving into the exploration of refugee-learner identity, a short examination of some theoretical connections between language and identity is imperative. Bucholtz \& Hall (2005) present a very clear investigation of this connection in their article "Identity and interaction: a sociocultural approach." Offering a broad, inclusive survey, this article promotes the concept of "sociocultural linguistics," an "interdisciplinary field concerned with the intersection of language, culture and society" (Bucholtz \& Hall 2005, p. 586). Defining identity as "the social positioning of self and other" (Bucholtz \& Hall 2005, p. 586), the authors stress the importance of contextual social interactions, roles and cultural values in the creation of individual's dynamic identities. Following this framework, identity as discussed in this paper refers to an ever-evolving, situationally-dependent concept, constantly being redefined by the individual.

Extended to the understanding of literacy, Hull \& Shultz's (2001) study of in- vs. out-ofschool learning echoes the crucial role of context, community and culture on the rise of multiple literacies. The authors stress that beyond narrow ideas of educational literacy, all acts of communication as social practice arise dependently from "activities diverse in function, form, and purpose" (Hull \& Schultz, 2001, p. 575). This, along with Bucholtz \& Hall's (2005) survey, illustrates the pervasiveness of context and language on forming both identities and literacies.

Although both of these concepts hinge on a combination of each individual's personal background and current context, a history of violence and displacement serves as a shared influence on refugees. For Southeast Asian refugees, specifically, this trauma, along with common cultural values, roles and religion will contribute to their unique status of refugee-learners.

\section{Violence \& Trauma}

One of the main influences on refugee-learner identity is trauma. Of the surveyed sources, the majority cited experiences of violence as a crucial factor which separates refugees from the 
normalized view of ESL learners. As forced migrants, "the violence to which refugees have been subjected and which has been executed at a physical, psychological and economic level, affects every aspect of what has been most meaningful in people's lives" (Freire, 1990, p. 3). In the ESLspecific environment, refugees' mental health, linguistic associations and second language acquisition skills are precipitated by these traumatic pasts (Freire, 1990; Kleinmann, 1984).

Psychological and emotional concerns are a central trait of refugee-learners. According to Finn (2010) and Adkins (1999), three resettlement stresses affect refugees' mental health to varying degrees. These are: migration stress, acculturative stress and traumatic stress, which correspond directly to unplanned movement, resettlement in an unfamiliar culture and violence from disaster or by willful human acts. As a result, many refugees may experience symptoms of post-traumatic stress disorder (PTSD) which affect them psychologically, socially and cognitively. Such permeating stresses may be either chronic or delayed. Regardless of the onset, however, the trauma experienced by refugees can present a debilitating mixture of depression, flashbacks, feelings of insecurity, inability to trust, and concentration and memory loss (Finn, 2010; Isserlis, 2000; Kleinmann, 1984).

According to Isserlis (2000), patterns of violence within immigrant and refugee communities can also be manifested in new sociocultural contexts. Whether the result of previous experiences or cultural acceptability, isolation through language or culture differences can affect refugees in resettlement, especially those who are victims of domestic violence. "While an overwhelming majority of violence is inflicted by men against women, violence is also perpetrated by women against men, within same-sex relationships, and intergenerationally" (Isserlis, 2000). Clearly, such acts can prolong experiences of violence and trauma for those who have already been resettled.

For Southeast Asian refugees, specifically, violence-induced trauma affects individuals differently than other groups due to cultural mores and religious beliefs. Not only do many view mental health issues as highly stigmatized, but the influence of Buddhism, Southeast Asia's most prominent religion, through its belief in karmic influence, serves as a construct for many to accept the effects of violence as simply the result of past lives' misdeeds (Gordon, 2011). Additionally, "Southeast Asian survivors of trauma often present with somatic symptoms, rather than discussing depression or grief, as the culture views body and mind as more interconnected than in Western culture and does not make a clear distinction between physical and emotional pain" (Gordon, 2011, p. 8). Canda (1990) corroborates this cultural difference, recording similar evidence of "somatization of distress" (p. 48) among Vietnamese, Lao, Cambodian and Hmong refugees.

When addressing trauma in Southeast Asian refugee communities, therefore, culturally relevant communication and knowledge of diversity between and within groups is key in both treatment and education (Canda, 1990). Although healthcare in refugees' new American cultural context emphasizes revealing traumatic events as a means of healing and empowerment, especially by women who have survived abuse, "breaking the silence" is not always a shared cultural value in Southeast Asian concepts of public vs. private pain (Gordon, 2011). As a result, language is not always used to give a voice to both past and ongoing pain and suffering.

Previous trauma may also manifest itself in several language-specific ways. First, as noted by Freire (1990), language is the most important aspect of culture. In refugees, linguisticallyrelated emotional memories can retain previous trauma that negatively affect identification with the society and culture of their L1, or native language (Freire, 1990; Werner-Smith \& Smolkin, 1995). Consequently, refugees must not only create a new voice and identity in English, but must also filter this new identity through the framework of their L1 and its engendered trauma. When 
combined with illiteracy and "under education" (Kleinmann, 1984, p. 215), many refugees suffer further linguistic oppression stemming from socio-economic or political factors, thus adding another layer of violence to their L1 experience (Freire, 1990).

In the ESL environment, histories of trauma will dramatically affect refugees' abilities to learn a new language. This is one of the most prevalent and significant findings echoed in many of the surveyed studies. Succinctly stated by Isserlis (2000), "since language learning demands control, connection, and meaning, adults experiencing effects of past or current trauma are particularly challenged in learning a new language" (p. 1). Whether linked directly to PTSD or other psychological stresses, cognitive ability of refugee-learners may be affected as a direct result of their circumstances which force them to not only learn new linguistic competencies but also construct new cognitive maps (Finn, 2000; Isserlis, 2000; Kleinmann, 1984).

Freire (1990) links these refugee-specific second language acquisition traits directly to the creation of identity. In the context of trauma, Freire states that the emotional internalization of a new language is required for life to start "being experienced in the second language" (p. 4). Beyond the mechanics of language, refugees must also work to create a complete identity which requires negotiation of previous experiences as well as the ability to express their histories of violence fully in a new linguistic context. Through this process, refugees can feel a sense of completeness in both languages (Freire, 1990).

\section{Gender \& Social Roles}

Forced migration "represents an interruption and frustration of natural life expectations. It is one of the most obvious instances of the complete disorganization of the individual's role system and the partial disturbance of social identity" (Kleinmann, 1984, p. 210). In the case of refugeelearners, sociocultural context represents the theater in which they further construct their identities. Linguistically-specialized development of refugees reflects their constant redefinition of gender and social roles through gendered language ideologies and adapted social and cultural literacies.

According to Warriner (2004), "gendered identities are constructed, negotiated, and deployed within specific situations and circumstances" (p. 182). Gendered language ideologies of Lao and Cambodian refugees in the Philadelphia area, as presented by both Gordon's (2009 \& 2011) and Skilton-Sylvester's (2002) respective research, highlight the intersection of language learning, traditional Southeast Asian gender roles and renegotiation in new target language communities. Within these narratives, ownership of English language proficiency as a result of second language socialization becomes a prime focus of refugee-learners in America. According to Gordon (2009), loss of male status after leaving their home-countries and the economic opportunities for women in refugee camps serve as the major catalyst for changing gender identities and family structure.

As English learners, men and women exhibit conflicting discourses. Although each strives for linguistic proficiency, their motivations and goals differ. Men can work to create identities based on nostalgic means to recapture former economic power and authority within the family and community. In the new American context, behaviors and exercises of traditional familial authority, such as domestic violence, are no longer acceptable parts of male power. Therefore, refugee men may seek linguistic ownership as a means to gain a newly defined identity similar to their premarginalized status. Conversely, women embrace English proficiency as a vehicle for increasing their agency, authority and economic power within both families and communities. Completely 
contrary to male Lao refugees, women embrace language as a means of empowerment and employment within new sociocultural environments (Gordon, 2009).

Women's identities further exhibit contextual dynamism. Along with newly found linguistic power, female refugees must also redefine their roles within the context of family relationships. According to one female Cambodian refugee, within cultural norms "a woman is supposed to act a certain way. We are wives and mothers-those are the roles. We never questioned any of it ... we accepted it" (Tenhula, 1990, p. 179). Although all ESL learners must continue to establish their identities in new sociolinguistic and sociocultural contexts, SkiltonSylvester (2002) explores the complex process through which Cambodian women synthesize new and old roles within family and community. Connecting real-life experience with ESL investment and motivation, this study illustrates ways in which women's shifting responsibilities as wives, mothers, daughters/sisters and workers reflect the layered, contextual identities as refugee women. Warriner (2004) adds that such constant re-creation of women's gender identity also needs to be supported by specific sociocultural and linguistic knowledges, echoing Gordon's (2009) specialized ownership of English by refugee women.

In expanding this idea of linguistic competencies as a direct result of sociocultural context, different refugee groups represent specific "cultures of literacy." As a bridge between the cognitive and cultural, refugee-learners "share norms of behavior and language use, and also share the attitudes toward learning and what it means to know a language" (Hornberger \& Hardman, 1991, p. 3). Engaged within the ESL environment, new linguistic input requires learners to cognitively process, encode, transfer and produce language through their existing L1 understanding. This may negatively affect refugees due to the side-effects of trauma and its potential to cause dissonance within the cognitive framework itself. However, refugee-learners, especially women, can "use both linguistic resources and their growing cultural knowledge to construct their individual identities within this local context ... and to comment on the structural (and power) relationships that exist in U.S. society" (Warriner, 2004, p. 192). Building on layered cultures of literacy, refugees will negotiate new linguistic identities as bilingual, bicultural learners.

\section{Bilingual, Bicultural Learners}

One final explored aspect of refugee identity is that of bilingual, bicultural learners. Although all ESL participants must negotiate a new culture and language, Southeast Asian refugees represent a unique population due to the aforementioned exploration of learner traits. Central to the development of their bilingual, bicultural identities are the roles of mutual L1 and English use as well as sociocultural and cross-cultural exposure.

As "learners," Southeast Asians, in general, exhibit clear differences in learning styles from other groups, as evidenced by Park's (2000) study of Cambodian, Hmong, Lao and Vietnamese students in the United States. Although some distinctions among these Southeast Asian groups are noted, several important commonalities exist, including preferences for visual, graphic learning methods and experiential, interactive and whole-body activities, as well as hands-on learning and small group activities (Park, 2000). Understanding these shared cultural traits of Southeast Asians not only informs ESL teaching (as explored in the next section) but also adds an essential cultural component upon which bilingualism and bicultural identities are constructed by each individual.

Additionally, building from the observations on "cultures of literacy" highlighted by Hornberger \& Hardman's (1991) research, refugees' L1 framework is extremely important in refugee-learner identity. Although Freire (1990) states that refugees must (temporarily) give-up 
aspects of themselves and their native language in order to learn an additional language, this is not a common theme throughout the surveyed research. In fact, many refugee-learners utilize their L1 and its cultural associations as well as input and support from other L1-English bilinguals as a means to forge their own linguistic identities (Hornberger \& Hardman, 1991; Werner-Smith \& Smolkin, 1995). Bilingualism can be effectively engaged within the ESL environment. Teaching and cultural approaches that highlight the mutual role of L1 and English will be presented in the next section.

Sociocultural and cross-cultural exposure are two other major factors in refugee-learner identity development. Introduced by Kleinmann (1984), much language acquisition by refugees occurs through cross-cultural encounters. This theme runs consistently through many of the studies, which highlights the socialization process that refugees must navigate in their daily lives. Freire (1990) states that "language has been said to be the mirror and map of society ... [which] reflects the values of needs of individuals ... [and] guides them into and through all the other behavior patterns of society" (p. 3). In the case of refugees, the American English environment will therefore serve as the context through which they can negotiate identities as bicultural citizens. Although a continuous process, refugee-learners' success will hinge on ESL programs' methods and means of engaging their multifaceted identities as individual bilingual, bicultural learners.

\section{Refugee-Learner Engagement: ESL Programs and Practitioners}

"The recognition that English is critical to surviving in the United States comes from one who has finally accepted that they cannot return home; [refugees] must create a life for themselves in the United States" (Finn, 2010, p. 588). Based on this sobering reality, ESL classes, therefore, become both a physical context for language learning and a crucial support structure for resettlement. In order to address refugee-learners' identities, stemming from the influence of trauma, changing roles within both family and community, as well as the need for cross-cultural English exposure, successful methods of engagement extend beyond simply teaching, to include attending holistically to the linguistic needs, mental well-being and healing of participants. Two interdependent aspects of refugee education which can positively influence and support learners are: a) ESL programs/curriculum, and b) teaching professionals and volunteers.

Informed by the profile of particular Southeast Asian refugee-learner traits from the first section, the following exploration is two-fold. First, findings related to general refugee ESL education from a variety of sources are presented. Additionally, where relevant, Southeast Asian culturally-specific topics are discussed.

\section{Program Responsibilities}

The following two quotes from John Tenhula's (1991) Voices from Southeast Asia succinctly state both the main criticisms of ESL programs experienced by refugees as well as alternatives to classroom study which some refugees choose for personal reasons:

The Method of [ESL] Instruction ... varies greatly in the way it is taught. Too often, respondents report that the classes are not relevant to their needs, are poorly taught, and are held at hours that are not conducive to learning. (p. 113) 
I learned English but not in a classroom. That's too much wasted time, it's too tiring. If you want to learn, you listen to people on the street, listen to the radio and TV, but also force yourself to speak. - Sirathra Som, Cambodian refugee (p. 180)

Through awareness of these critiques and refugees' attitudes towards classroom study, ESL programs bear the responsibility to adaptively and effectively support both learners and teachers.

As evidenced in the surveyed research, on the global level, ESL programs can directly benefit refugees in two main ways, by: a) creating a supportive community/physical environment, and $b$ ) adjusting the curriculum to balancing schooled vs. non-schooled (Warriner, 2004, p. 181) competencies. Please note that some of the following methods can be identified as ingredients of specific language teaching approaches, such as community language teaching or task-based learning. However, in an attempt to avoid the baggage of approach-laden criticism and prescriptive language teaching syllabi, techniques will be introduced separately, rather than as components of previously established theories and practices. Finally, ESL programs must offer specific support to instructors. Whether they are paid professionals or volunteers, the responsibility of training and educating the educators belongs at the program level.

Support and Environment. Overall, the essential focus of refugee ESL programs should be the creation of a support structure and stable community for learners. Kleinmann's (1984) historical survey begins laying a conceptual foundation for this specific model by stating that "the involuntary migration of Indochinese refugees requires us to consider the external factors in designing and operating ESL programs. Support service must be available to alleviate various stresses and facilitate sociocultural adjustment" (p. 217).

Building on this foundation, various studies have explored different means to achieve this goal, exhibiting common findings in distinctive contexts. First, linguistic and cultural support through shared L1 has been shown as a successful method for ESL programs. In outlining the creation of a bilingual, bicultural ESL program, Werner-Smith \& Smolkin (1995) introduce a major element of refugee-focused ESL: peer language and cultural support through counselors sharing both participants' L1 and English. This allows learners within the program to participate in the cultures of both languages in order to gain empowerment by bridging between the L1 context and their current situation as well as aiding in bilingual, bicultural identity development (WernerSmith \& Smolkin, 1995; Potocky-Tripodi, 2002). Echoed by Hornberger \& Hardman (1991), Cambodian refugee women in ESL programs benefited by having a Cambodian woman who was empathetic to the students' situations and understood their L1 as their instructor. As members of the same refugee community, this pairing of teacher and students creates "a language learning environment (a culture of literacy) built upon the fusion of two different approaches to language learning and literacy acquisition: cognitive skills and cultural practice" (Hornberger \& Hardman, 1995, p. 23).

In his survey "Therapeutic use of writing and other media with Southeast Asian refugees," Edward Canda (1990) offers means of support which extend beyond both English and L1 use to explore other "therapeutic facets of teaching ESL" (p. 50). He presents methods of teaching that synthesize writing with traditional (ethnic-specific) craft, art media and modes of healing, since "Southeast Asian people have traditional ways of employing writing and design that do not conform to conventional Western concepts of healing" (Canda, 1990, p. 51). Examples of Hmong narrative needlework with embroidered captions and beliefs of healing through Buddhist magical and religious writings are offered. In the ESL context, the incorporation of these culturally- 
appropriate media not only build a bridge between English and refugees' L1, but also create a more comfortable environment in which language study through familiar modes of expression can positively affect the well-being and mental health of refugee-learners. Employing such methods is one way of unlocking truly therapeutic outcomes of ESL.

Widening the scope, refugee-only programs have been advocated to address the traumatic histories of learners. Such programs, regardless of participants' L1, have been characterized as comforting and nurturing environments which allow refugees to connect with others in similar situations. This is especially helpful as refugees tend "naturally to reject everything that is new that could threaten even further his/her very shaky sense of identity" (Freire, 1991, p. 5). This model is also supported by Werner-Smith \& Smolkin's (1995) findings, shown through the mixed groups of Southeast Asian first- and second-generation refugees enrolled in a summer ESL precollegiate program. Learners in this program were aided by sharing similar backgrounds and experiences, which allowed both language and culture instruction to be approached in a safe and sensitive manner, respecting the effects of violence and trauma on participants' personal experiences (Werner-Smith \& Smolkin, 1995). Attention to these means of engaging students will be further discussed in the next section on teacher-specific approaches.

Safe classrooms and access to ESL must also be addressed on the program-level. Fostering a classroom culture that allows voluntary and varying degrees of student participation has been shown as a proven way to begin engaging reticent learners, who may feel overwhelmed by certain topics or practices. When combined with permitting L1 use within class, students may feel more comfortable among their classmates (Isserlis, 2000). Additionally open, fluid classrooms may have a positive effect on refugee learning by allowing students to attend as time permits and enabling more experienced students to mentor newcomers as "experts." However, the lack of stability of this arrangement can negatively affect sense of community and classroom structure. In order to aid the creation of stability in the lives of refugees, more structure, familiar classmates and reliable, non-transient instructors are key to student success as well as building learners' confidence and trust (Finn, 2010). As far as access, taking into account participants' personal responsibilities to families, children and employment for scheduling class times is especially important. For those without their own transportation or who are unable to be out at night (due to safety or other concerns), classes during the daytime or on weekends can encourage learner participation (SkiltonSylvester, 2002). Thus, the many aspects of learner identity and commitment should be factored into program offering times.

Curriculum: Schooled vs. Non-schooled Competency. On the curricular level, ESL programs must also negotiate a balance of schooled vs. non-schooled competencies (Atkinson, 2014; Hull \& Schultz, 2001; Warriner, 2004) as well as learner-centered traits, such as interest and investment. As previously illustrated, refugee-learners may immigrate to the United States with varying levels of L1 competency and education. As evolving bilingual, bicultural individuals, it is extremely important that multiple literacies of learners be nurtured for development of sociolinguistic identity in the classroom as well as in daily life. This will ensure that refugees acquire both functional literacy skills while also being able to negotiate new cultural landscapes (Atkinson, 2014, p. 13). In relation to curriculum development, the surveyed studies have described several types of approaches, which involve both classroom-specific and daily-life learning to target linguistic proficiency.

Within the classroom, evidence suggests that refugee-learners' English acquisition can be increased in several ways. Above all, course content should present language which is directly 
relevant to the everyday lives of learners and immediately applicable to their current situation (Kleinmann, 1984; Skilton-Sylvester, 2002). Introducing issues and authentic materials related directly to American culture, healthcare, childcare, employment and daily routines, such as shopping, should be standard components of the ESL curriculum. "These activities give learners opportunities to discuss issues of personal interest and concern with others to solve problems related to survival, family and employment ... [while constituting] part of the process of developing needed competencies using the English language" (Adkins, Sample \& Birman, 1999, p. 4). In addition, topical relevance has been shown as a key to engaging the dynamic identities of learners outside of the classroom, as many refugees strive to become workers and contributing members of their immediate communities and American society-at-large. By employing these methods, the ESL context becomes "a social and educational journey made meaningful by a learner's sense of (emerging) identity" (Atkinson, 2014, p. 14).

Despite findings that suggest the positive influence of work-related lessons in the classroom on learner interest, Warriner (2004), Potocky-Tripodi (2002) and Atkinson (2014) warn that ESL programs should invest in the long-term goals of refugees themselves rather than just quick training for dead-end jobs. Due to the involvement of government and resettlement agencies, current programs are sometimes forced to meet limited mandated targets of "successful employment" instead of designs which favor learner development and personal achievement. "By prioritizing the need to find entry-level employment quickly at the expense of creating opportunities for learning English and finding a job that will foster true economic and social mobility ... [an ESL program] assumes and promotes a deficient view of its students" (Warriner, 2004, p. 192). Therefore, a balance between topics and program-student goals must be developed in order to create more learner-centered ESL environments.

Other aspects of the proposed curriculum-specific linguistic measures include: consistency of classroom lessons, de-emphasizing formal language rules, and providing authentic language exposure (Kleinmann, 1984). Beginning in the classroom, these measures aim to bridge both schooled and non-schooled competencies by employing cognitively-focused presentation as well as meaningful and relevant instruction in a "learner-centered approach that incorporates learners' linguistic interactions outside the classroom" (Finn, 2010, p.592).

Consistency of lesson presentation and student expectations should be central to refugee ESL curricula. Given the possible short- and long-term memory impairment as a result of PTSD, refugee-learners will require different approaches than mainstream ESL students for targeting retention and understanding of new linguistic input. "Repetition is a key factor in fostering second language acquisition ... [giving] students a sense of consistency and [reinforcing] the material" (Finn, 2010, p. 593). Extrapolated to a higher design level, expectations of the students founded on lesson routine and consistent classroom operation could also help address students' cognitive difficulties through establishing a set rhythm for learning.

Leaning more toward "acquisitional" than "schooled," Kleinmann (1984) introduces a framework of refugee ESL which lessens the stress on teaching formal linguistic rules. Based on Krashen's monitor model and the assumption that refugee-learners may lack formal L1 linguistic knowledge, Kleinmann (1984) states that L2 learning environments should therefore de-emphasize the formal rules of English and focus more on the interdependence of language and sociocultural development. This shift in focus from the formal to the everyday use of English in refugee ESL is further evidence of the importance of both authentic instructional materials within the classroom and sociolinguistic experience and language use outside of it. 
Presented in several studies as an aid to the resettlement process, non-schooled competency can be encouraged through a combination of ESL program factors. In the most explicit model, Kleinmann (1984) proposes that "refugees can be sensitized to American culture, institutions, and systems, and be exposed to meaningful out-of-class intake environments which complement inclass language acquisition activities" (p. 217). In order to achieve this sociolinguistic synthesis of schooled and non-schooled acquisition, ESL programs should combine both classroom learning and community support.

Other studies also approach the monitoring of non-schooled acquisition as a means of integrating ESL and English language use within the lives of learners. In addition to simply employing topical content which can connect learners to immediately useful language, ESL programs can benefit from examining "learners' daily lives in order not only to understand from where second language input comes, but also to gain greater understanding of the learners' literacy needs" (Finn, 2010). Non-schooled language learned outside of the classroom, therefore, becomes key to both learner use and guidance for ESL programs, as application of this knowledge in the classroom can be used to increase the multiple literacies and contexts in which refugee-learners are conversant (Hull \& Schultz, 2001). As evidenced by Warriner (2004), Skilton-Sylvester (2002) and Finn (2010), self-experienced competencies and linguistic exposure are extremely crucial elements in the development of refugee-identity. In the spirit of Kleinmann's (1984) outline of cross-cultural exposure to expand the classroom beyond a physical space, ESL programs should aim to holistically support schooled and non-schooled learner language acquisition to create a language learning environment which focuses "competency-based approaches ... to help keep students in the present rather than returning to the painful past" (Finn, 2010, p. 592).

Instructor Support. Aside from refugees, instructors, themselves, require specific support from ESL programs. Given the unique identities of refugee-learners, consideration to those teaching them is equally as important for successfully facilitating personal learning and growth of students. Although Potocky-Tripodi (2002) suggests programs that employ specially-trained professional teachers, rather than volunteers, to instruct refugees, there are more practical (and financially viable) means of support.

Perry \& Hart (2012) explore ways in which ESL programs can prepare paid and volunteer teachers to better serve refugee populations. In their study, the authors found that many teachers felt severely lacking in skills related to refugee-specific English instruction, despite teaching credentials and/or program-specific training. In the words of surveyed teachers, program-level improvements related to in-service development, targeted/contextual training for topics and teaching content, apprenticeship/mentoring experiences, more resources for self-education, and refugee-specific cultural education would be beneficial to improve teacher confidence and learner engagement (Perry \& Hart, 2012).

On the program level, such changes would allow ESL instructors more opportunities to hone their classroom skills and expand their understanding of refugee-learners' cultures and identities. Forming a strong foundation for practitioners is essential for teachers, given their varied, holistic roles in the lives and education of learners.

\section{Teacher's Roles in Refugee Learning}

The role of the teacher within the refugee ESL environment is both multifaceted and dynamic. As an extension of the previously explored environmental-, curriculum- and instructor-specific 
program-level recommendations, ESL professionals and volunteers serve as the human face of refugee-learners' connection to language and culture in America. Of the many characteristics of language teachers, those found especially important within the surveyed research center on the roles of assessor, resource, manager, designer, monitor and collaborator. These will be separated into two broader categories: a) teacher-as-advocate and b) teacher-as-implementer.

Teacher-as-Advocate: Assessor \& Resource. Stemming from the potential of refugees' identity as a product of trauma and ESL programs' responsibilities to provide a safe and supportive learning environment, practitioners working directly with refugee-learners should serve as advocates. Normally relating to assessment of linguistic progress and language-specific resources, refugee ESL instructors can apply their roles as assessor and resource to the mental health of their classroom constituents. Above all, teachers should become aware of symptoms of mental illness and trauma which can afflict refugees as a result of PTSD or domestic violence and, in turn, refer them to the appropriate healthcare professionals (Adkins et al., 1999; Canda, 1990). This allows instructors to assess both the learners' psychological health as well as appropriate content of their courses. In relation to learners and learning material, this role of assessor will be intrinsically connected to the role of resource.

For learner support, the combination of these roles is not meant to elevate the teacher to a therapist or counselor (Finn, 2010), but instead position ESL instructors as "an integral part of a larger network of providers that includes mental health professionals" (Adkins et al., 1999, p. 3). Through familiarity with refugee-specific health issues and individual student's experiences, teachers can better advocate for students' well-being. Key to this role is finding out about community resources, laws pertinent to refugee needs and services available in dealing with trauma and other concerns, such as domestic violence. Growing teacher awareness can not only help connect refugee-learners to proper health professionals, but can also be manifested in providing lists of these resources and fostering learner skills to better access them. Additionally, with knowledge of potential concerns within refugee communities and a larger support system to address them, ESL practitioners can aid in creating a greater dialogue "about culture-based approaches of dealing with the issue of violence and learners" (Isserlis, 2000). As Canda (1990) succinctly states, ESL practitioners also "serve as cultural brokers for students, helping them understand American customs and expectations" (p. 54).

In respect to learning material and classroom topics, assessment and resources are also key roles of instructors. Building on the teacher's place in creating a safe environment, "educators should understand that [although not all refugees have experienced trauma] certain topics generally discussed in adult ESL classes (e.g. family and health) can cause learner discomfort because of past and present abuse" (Isserlis, 2000). Assessment of topics and activity design within daily classroom operation must therefore be managed closely by teachers in order to respect learners' varied personal and cultural experiences. Although overlapping with teacher-as-implementer, the more sensitive nature of content and presentation require the more teacher-specific skills of assessment and discrimination.

Resources, as already introduced in curriculum exploration, should be monitored on a dayto-day basis by instructors. In combination with the resources provided for refugee-learner health and well-being, teachers can work to integrate those into lessons and engage learners in less invasive ways to both introduce relevant topics as well as provide linguistic practice for accessing community support (Adkins et al., 1999; Isserlis, 2000). With mindfulness and knowledge of refugee-specific health needs and the broader network of assistance, "teachers' understanding of 
the effects of trauma on learning ... should help to make the classroom a safe place and learning more possible for adult language learners" (Isserlis, 2000).

Teacher-as-Implementer: Manager, Designer, Monitor \& Collaborator. The view of the teacher-as-implementer is a varied role dealing directly with managing, designing, monitoring and collaborating. By actively carrying out the curriculum and engaging learners, all of these functions can be categorized under the skillset of teacher implementation.

Classroom management is an important characteristic for ESL teachers of refugees. In order to foster a community of learners, teachers-as-managers can positively affect students through employing classroom procedures to create a safe and consistent environment, using appropriate content and activities, and monitoring students' goals and interests.

Managing procedure is the manifestation of many of the curriculum-level suggestions for refugee ESL programs in the daily routine of classrooms. Above all, proper management will create "an environment in which students feel empowered" (Finn, 2010, p. 591). Environmentally, teaching professionals should be conscious of the physical learning space. By familiarizing students with surrounding amenities, leaving doors ajar or allowing students the freedom to leave the room or opt out of uncomfortable activities, if necessary, learners will feel a sense of agency (Isserlis, 2000). Additionally, repetition and material review can begin building a sense of consistency within the flow of class activity. This is especially important for those who may be experiencing cognitive difficulties (Finn, 2010). Through managing tasks and activities, teachers can create a familiar routine. This will allow refugee-learners to "view the classroom as a safe and predictable place ... [thus] building community among and safety for learners and practitioners" (Isserlis, 2000).

Choosing appropriate, motivational content and activities is another important aspect of both teacher-as-designer and manager. In order to connect with learners, practitioners should be aware of student interest and out-of-class experiences. Building on personal meaningfulness to each individual learner, teachers can boost participation in class by treating English language acquisition as a social and cultural journey complementing refugees' own "sense of adjustment to ... society and their emerging sense of self" (Atkinson, 2014, p. 10). Additionally, playing into the need for authentic, engaging materials, teachers can increase learner investment through making sure that learners are topically engaged (Finn, 2010; Skilton-Sylvester, 2002). Although this point is stressed on the curriculum-level as well, in the day-to-day operation of the classroom teachers should take responsibility for fine-tuning materials for student use. This is extremely important in employing group work and other types of interactive tasks to increase student interaction while lowering the overall affective elements of the classroom (Kleinmann, 1984; Werner-Smith \& Smolkin, 1995).

For Southeast Asian refugees, especially, certain cultural learning preferences should also be taken into account by teachers in relation to their roles as designers. As previously noted, Park (2000) recommends visual and graphic teaching; whole-body, experiential teaching; hands-onlearning; and small group activities. In combination with Canda's (1990) and Werner-Smith \& Smolkin's (1995) findings, ethnically-appropriate modes of narrative writing and arts should be integrated into lessons to increase meaningfulness to the participants.

Studies have also illustrated that active monitoring and collaboration by teachers leads to familiarity with learner differences, aptitudes and interests. By developing rapport with students, teachers can effectively establish a learner-centered classroom through creating opportunities for interaction which reinforce linguistic development as well as introduce communication and 
comprehension strategies (Finn, 2010; Kleinmann, 1984). Building on this foundation, mindful advocacy and implementation by teachers can foster environments which address refugees' dynamic identities while supporting their entitlement to education, language development and the "right to speak" outside of the classroom (Skilton-Sylvester, 2002).

\section{Conclusion}

Within the American refugee population, Southeast Asians represent a unique group due to shared experiences of trauma as well as cultural, religious and social commonalities. All of these traits influence each individual survivor's life while also playing a central role in their evolving identities within the new linguistic environment. As English learners, therefore, their experience as a distinct cohort of refugee-learners should inform the way in which they are supported by ESL programs and practitioners.

Language is clearly a vital link in the resettlement of Southeast Asian and all other refugees. Connected directly to individual development and acculturation, the ESL environment plays an active part in refugee-learners' identity creation as they overcome personal histories and face new challenges in an unfamiliar context. Through awareness of possible traumatic pasts and current renegotiation of gender-social roles, ESL programs can effectively support refugee-learners through reinforcing both linguistic and life skills. On the curriculum-level, creating supportive environments and addressing schooled and non-schooled competencies have been shown to benefit students. Within classrooms, teachers can enact these greater goals on a micro-level through advocacy and implementation. As a result, an understanding of refugee-learner identities can positively target "the long-term participation and investment of adult ESL learners ... [through] seeing the classroom as a real place where the multiple selves of learners are central to teaching, learning, and program development" (Skilton-Sylvester, 2002, p. 22).

This review has been a means of gaining personal insight and perspective on both traits and identities of Southeast Asian and general refugee-learners that many American ESL practitioners will potentially instruct in the coming years. Although the surveyed studies have highlighted crucial aspects of the interaction of refugee-learners in the ESL environment, many possibilities for deeper investigation remain. With learners as the focus of most research on this topic, further explorations of teacher roles and behaviors, program design, and explicit teaching methodologies would serve to create a more holistic view of the dynamic interaction among refugees, language programs and teachers. In the face of ongoing political unrest and oppression in the world, this knowledge will inform and enable ESL practitioners to better support the linguistic empowerment and resettlement of refugees in the United States.

\section{Acknowledgements}

Throughout the writing process of this article, I received guidance and support, both academically and personally, from several people who deserve more thanks than I can offer. First, Dr. Christopher Jones (Carnegie Mellon University) tirelessly advised my research methodology while reviewing my writing from the inception of the article until its first submission. Dr. Candace Skibba (Carnegie Mellon University) and Mr. Andrew Decker (Chatham University, English Language Program) offered invaluable teaching perspectives which helped inform my exploration as well as my professional development as an ESL/EFL teacher. Additionally, my parents, Ralph and Elizabeth Perlman, constantly supported and encouraged me as I pursued my MA and worked 
to complete and edit my writing. (Extra special thanks to my mom who thoughtfully donated her professional proofreading and editing skills to the cause of this paper.) Finally, ChingWei Lin offered both moral support and motivation during the home stretch of revising and editing this article for final submission. Thank you, all.

\section{References}

Adkins, M. A, Sample, B., \& Birman, D. (1999). Mental health and the adult refugee: The role of the ESL teacher. National Clearinghouse for ESL Literacy Education.

Atkinson, M. (2014). Reframing literacy in adult ESL programs: Making the case for the inclusion of Identity. Literacy and Numeracy Studies, 22(1), 3-20. doi: 10.5130/Ins.v22i1.4176

Bucholtz, M., \& Hall, K. (2005). Identity and interaction: A sociocultural linguistic approach. Discourse Studies, 7(4), 585-614. doi: 10.1177/1461445605054407

Canda, E. R. (1990). Therapeutic use of writing and other media with Southeast Asian refugees. Journal of Independent Social Work, 4(2), 47-60. doi: 10.1300/J283v04n02_04

Finn, H. B. (2010). Overcoming barriers: Adult refugee trauma survivors in a learning community. TESOL Quarterly, 44(3). doi: 10.5054/tq.2010.232338

Freire, M. (1990). Refugees: ESL and literacy: Trying to reinvent the self in a new language. Canada's Journal on Refugees, 10(2), 3-6.

Gordon, D. (2009). She's American now, I don't like that: Gendered language ideologies in a Laotian American community. Journal of Southeast Asian American Education and Advancement, 4(1), 1-19. doi: 10.7771/2153-8999.1092

Gordon, D. (2011). Trauma and second language learning among Laotian refugees. Journal of Southeast Asian American Education and Advancement, 6(13), 1-18. doi: 10.7771/21538999.1029

Hornberger, N., \& Hardman, J. (1991). Literacy as cultural practice and cognitive skill: Biliteracy in a Cambodian adult ESL class and a Puerto Rican program. In D. Spencer (Ed.), Adult biliteracy in the United States (pp. 147-170). Center for Applied Linguistics and Delta Systems.

Hull, G., \& Schultz, K. (2001). Literacy and learning out of school: A review of theory and research. Review of Educational Research, 7(4), 575-611.

Kleinmann, H. H. (1984). Understanding refugee second language learning: The language teacher. The Japan Association of Language Teachers, 6(2), 209-219.

Park, C. C. (2000) Learning style preferences of Southeast Asian students. Urban Education, 35(3), 245-268. doi: 10.1177/0042085900353002

Perry, K. H., \& Hart, S. J. (2012). I'm just kind of winging it. Journal of Adolescent \& Adult Literacy, 56(2), 110-122. doi: 10.1002/JAAL.00112

Potocky-Tripodi, M. (2002). Language, education, and economic well-being. In P. Miriam (Ed.), Best practices for social work with refugees \& immigrants (pp. 356-415). Columbia University Press.

Skilton-Sylvester, E. (2002). Should I stay or should I go? Investigating Cambodian women's participation and investment in adult ESL programs. Adult Education Quarterly, 53(1), 926. doi: 10.1177/074171302237201 
Tenhula, J. (1991). Voices from Southeast Asia: The refugee experience in the United States. Holmes \& Meier.

Warriner, D. (2004). Multiple literacies and identities: The experiences of two women refugees. Women's Studies Quarterly, 32(12), 179-195.

Werner-Smith, A.M., \& Smolkin L.B. (1995). An ESL/bilingual/bicultural pre-collegiate program for Southeast Asian refugee high school students. The Bilingual Research Journal, 19(4), 395-408.

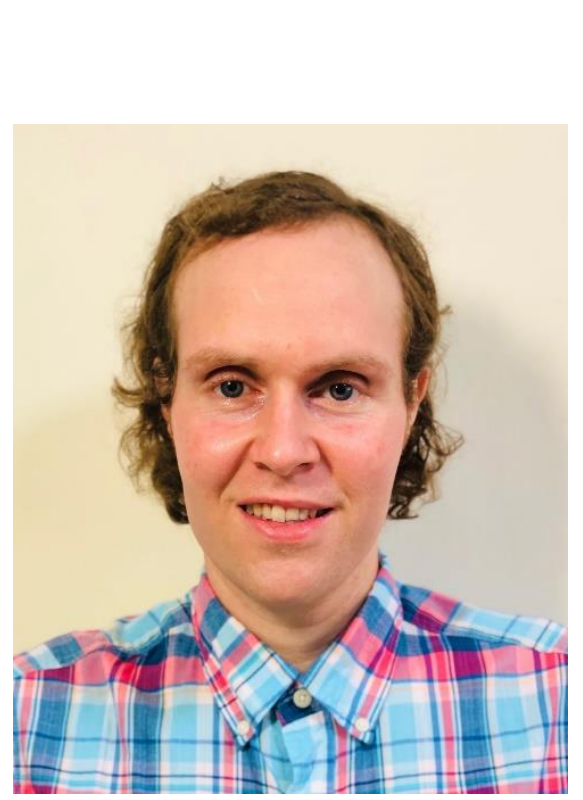

\section{About the Author}

Andrew Perlman, holds an MA in Applied Second Language Acquisition and TESOL Certification from Carnegie Mellon University (2016). Throughout his course of study, he volunteered among underserved refugee communities in the Greater Pittsburgh Area as an English tutor and in-home mentor. Additionally, he has spent much time studying Thai language and travelling in Thailand and other Southeast and East Asian countries. It is from these experiences of language teaching and learning as well as seeing first-hand the extent of refugee diaspora in the United States and Asia that he became particularly interested in refugees as a unique demographic of language learners. He hopes his work to compile and critique existing research on refugee-learners and language education will contribute to the ongoing dialogue among teachers, volunteers and ESL program developers to enhance and vitalize methods and approaches of supporting refugee communities within the United States.

After working 18 years in academic libraries, Andrew relocated to Taiwan to become an English teacher in late 2019. He currently resides in New Taipei City, Taiwan, happily teaching elementary school students and adults. In addition, he constantly works on improving his Mandarin Chinese and skateboarding skills. In the future, he hopes to continue his pursuit of writing and research in language-related fields. 


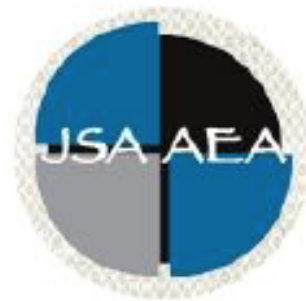

Vol.15 Iss.1 (2020)

\title{
Journal of Southeast Asian American Education and Advancement
}

\author{
www.JSAAEA.org
}

\section{Editor}

Dr. Wayne E. Wright

Purdue University

Associate Editors

Dr. Chhany Sak-Humphry

University of Hawaii at Manoa

Dr. Phitsamay Sychitkokhong Uy

University of Massachusetts, Lowell

\section{Book Review Editor \\ Dr. Vichet Chhuon}

University of Minnesota

Creative Works Editor

Bryan Thao Worra

Lao Assistance Center

\section{Journal Manager \\ Fang Gao \\ Purdue University}

\section{Editorial Review Board}

Dr. Steve Arounsack

California State University, Stanislaus

Dr. Sovicheth Boun

Salem State University

Dr. Virak Chan

Purdue University
Dr. Carl L. Bankston III

Tulane University

Dr. Phala Chea

Lowell Public Schools

Dr. George Chigas

University of Massachusetts, Lowell 


\author{
Dr. Loan Dao \\ University of Massachusetts Boston \\ Dr. Changming Duan \\ University of Missouri-Kansas City \\ Dr. Sothy Eng \\ Lehigh University \\ Dr. Vincent K. Her \\ University of Wisconsin, Eau Claire \\ Dr. Peter Nien-Chu Kiang \\ University of Massachusetts, Boston \\ Dr. Kevin K. Kumashiro \\ University of Illinois, Chicago \\ Dr. Ha Lam \\ Independent Scholar \\ Dr. Jonathan H. X. Lee \\ San Francisco State University \\ Dr. Monirith Ly \\ Royal University of Phnom Penh \\ Dr. Bic Ngo \\ University of Minnesota \\ Dr. Leakhena Nou \\ California State University, Long Beach \\ Dr. Mark Pfeifer \\ SUNY Institute of Technology \\ Dr. Loan T. Phan \\ University of New Hampshire \\ Dr. Karen Quintiliani \\ California State University, Long Beach \\ Dr. Angela Reyes \\ Hunter College \\ The City University of New York \\ Dr. Fay Shin \\ California State University, Long Beach \\ Dr. Christine Su \\ College of San Mateo \\ Dr. Alisia Tran \\ Arizona State University \\ Dr. Khatharya Um \\ University of California, Berkeley \\ Dr. Kim Tran \\ University of California, Los Angeles, \\ Glendale Community College \\ Dr. Molly Wiebie \\ The University of Texas at Austin
}

Dr. Hien Duc Do

San Jose State University

Dr. Sophal Ear

Occidental College

Dr. Jeremy Hein

University of Wisconsin, Eau Claire

Dr. Nancy H. Hornberger

University of Pennsylvania

Dr. Peter Tan Keo

New York University

Dr. Yvonne Kwan

San Jose State University

Dr. Ravy Lao

California State University, Los Angeles

Dr. Stacey Lee

University of Wisconsin, Madison

Dr. Sue Needham

California State University, Dominguez Hills

Dr. Max Niedzwiecki

Daylight Consulting Group

Dr. Clara Park

California State University, Northridge

Dr. Giang Pham

University of Massachusetts Amherst

Dr. Malaphone Phommasa

University of Clifornia Santa Barbara

Dr. Kalyani Rai

University of Wisconsin-Milwaukee

Dr. Cathy J. Schlund-Vials

University of Connecticut, Storrs

Dr. Nancy J. Smith-Hefner

Boston University

Dr. Yer J. Thao

Portland State University

Dr. Monica M. Trieu

Purdue University

Dr. Silvy Un

Saint Paul Public Schools

Dr. Linda Trinh Vo

University of California, Irvine

Dr. Yang Sao Xiong

The University of Wisconsin-Madison

Dr. Zha Blong Xiong

University of Minnesota 


\section{Doctoral Student Editorial Review Board}

\author{
Diana Chandara \\ University of Minnesota-TwinCiteis \\ Linh Dang \\ University of Rochester \\ Annie BichLoan Duong \\ San Joaquin County Office of Education \\ Jacqueline Mac \\ Indiana University \\ Vanessa Sovanika Na \\ University of California SanDiego \\ Khoi Nguyen \\ George Mason University \\ Linda Marie Pheng \\ University of Wisconsin-Madison \\ Latana Thaviseth \\ University of California Los Angeles \\ Melissa Vang \\ San Diego State University \\ Soua Xiong \\ San Diego State University \\ Claremont Graduate University
}

\author{
Kassandra Chhay \\ University of Minnesota-Twin Cities \\ Bao Diep \\ University of Minnesota-Twin Cities \\ Nielson Hul \\ Cornell University \\ Dung Minh Mao \\ University of Minnesota-Twin Cities \\ Hoa Nha Nguyen \\ Boston College \\ Thien-Huong Ninh \\ University of Southern California \\ Krissyvan Truong \\ Claremont Graduate University \\ Mai Vang \\ University of Massachusetts Boston \\ Thong Vang \\ University of Minnesota-Twin Cities
}

